\title{
MODEL PEMBELAJARAN LOMPAT TINGGI GAYA FLOP PADA SISWA SEKOLAH MENENGAH PERTAMA
}

\author{
Sabila Nur Masturah \\ STIT Al Marhalah Al Ulya \\ Email : sabilanurm@gmail.com
}

\begin{abstract}
The aim of this research and development is to produce the Flop Style High Jump learning model for junior high school students. This research uses research \& development (R \& D) research methods from Borg and Gall. The subjects in this research and development are Jakarta Junior High School students, which consist of 20 limited testing students (small group trials), 40 main trial athletes (field testing) and 50 Test effectiveness models.

The stages in this study were: (1) needs analysis, (2) model development planning, (3) expert judgement, (4) limited testing (small group trials), (5) main trials (large group / field trials), (6) effectiveness testing. Effectiveness testing using the High Jump Style Flop motion assessment test to determine the level of high jump ability in the flop style of junior high school students, before and after the treatment of the flop style high jump learning model. From the preliminary tests performed, the average flop style jump learning average was 42.47 , then after being given treatment in the form of a flop style high jump learning model, the flop style high jump level was 83.75. Then the flop style high jump learning model is effective in improving flop style high jump learning for junior high school students.

Based on the results of the development, from the results of field trials and discussion of research results it can be concluded that: 1) With this flop style high jump learning model, students can learn and carry out learning effectively and efficiently. 2) With the flop style high jump learning model material that researchers have developed, students can understand theory material and high jump practice quickly and correctly.
\end{abstract}

Keywords: Development, Model, Learning, High Jump Flop Style

\section{Pendahuluan}

Cabang olahraga atletik terbagi kedalam beberapa nomor yaitu: nomor lari, lompat dan lempar. Berlari, melompat juga melempar merupakan sifat alamiah manusia. Pada zaman dahulu kemampuan ini dimiliki oleh manusia untuk mempertahankan diri, untuk berburu dan yang lainnya. Berdasarkan sifat alamiah tersebut seharusnya pembelajaran atletik di sekolah digemari atau siswa antusias dalam mengikutinya. Cabang atletik sendiri merupakan cabang yang sangat menarik untuk dikembangkan dalam hal metode dan variasi latihan. Sesuai pendapat Houcine Benzidane dkk, (2016) Athletics games are considered among events that attracted attention in the area of research thing which led to the improvement in various training methods.

Lompat merupakan nomor dalam cabang olahraga atletik yang didalamnya terdiri dari nomor: lompat jauh, lompat jangkit, lompat tinggi dan lompat tinggi galah. Lompat tinggi merupakan salah satu nomor cabang olahraga atletik yang unik, karena awalan lompat tinggi gaya flop ini diharuskan menikung/kurva. 
Lompat tinggi merupakan cabang pembelajaran atletik yang pada umumnya pembelajaran olahraga cabang atletik yang kurang diminati oleh siswa. Dalam lompat tinggi diperlukan penguasaan dalam 3 hal, seperti yang dijelaskan oleh James Becker dkk (2012), dimana membagi dalam beberapa fase yakni: A high jump consists of three distinct phases: the approach run, the plant and takeoff, and the flight and bar clearance. Tiga fase ini adalah hal yang harus dikuasai. Pada fase lari dan melompat merupakan tahap yang penting, seperti yang dijelaskan Ch. Raja Rao (2014) bahwa The most important and critical phases of the jump are the approach run and takeoff, the bar clearance is a direct consequence from previous phases. Lebih jauh lagi WenZu Song (2013) menjelaskan dalam hasil penelitiannya bahwa the jumping speed and vertical speed influence the jumping score in a deep degree, it also validates the importance of the jumping angle. Dalam penelitianya dijelaskan bahwa pada fase selanjutnya perlu diperhatikan bahwa sudut lompatan mempengaruhi keberhasilan lompatan.

\section{Metodologi}

Tujuan penelitian ini untuk dapat mengembangkan model pembelajaran lompat tinggi gaya flop pada siswa SMP. Secara operasional tujuan penelitian pengembangan ini adalah : 1) Mendapatkan model pembelajaran yang tepat untuk mengembangkan dan menerapkan materi pembelajaran lompat tinggi gaya flop pada siswa SMP. 2) Memperoleh data empiris tentang efektifitas model pembelajaran lompat tinggi gaya flop pada siswa SMP. 3) Memberikan variasi pembelajaran gaya flop pada lompat tinggi.

Tujuan akhir dari penelitian pengembangan ini adalah menghasilkan produk berupa buku yang berisikan model pembelajaran lompat tinggi gaya flop khususnya untuk siswa SMP, sehingga dapat menjadi pedoman bagi para pelatih, yaitu : 1) Efektif, artinya dimana dalam meningkatkan efektifitas dalam berlatih untukmengembangkan pembelajaran lompat tinggi gaya flop, khususnya untuk siswa SMP. 2) Efesien, maksudnya kelengkapan bantuan berlatih, dimana dengan perencanaan biaya dan waktu yang tepat dapat diperoleh hasil yang optimal dalam penguasaan materi lompat tinggi gaya flop. 3) Menarik, artinya dimana dalam berlatih memiliki daya tarik sehingga atlet termotivasi untuk berlatih lebih maksimal.

Penelitian pengembangan model pembelajaran lompat tinggi gaya flop pada siswa SMP ini menggunakan metode penelitian dan pengembangan atau research and development (R\&D) dari Borg dan Gall. Menurut sugiyono (2011:297) metode penelitiandan pengembangan atau research and development (R\&D) adalah metode penelitian yang digunaka untuk menghasilkan produk tertentu dan menguji keefektifan produk tersebut.

Penelitian ini menggunakan pendekatan kualitatif dan kuantitatif, yang merupakan pendekatan dengan tujuan menemukan jawaban dari masalah melalui rumusan yang telah di jabarkan pada pendahuluan yaitu model pembelajaran lompat tinggi gaya flop pada siswa SMP.

Penelitian dan pengembangan ini menggunakan pendekatan kualitatif dan kuantitatif serta menggunakan model pengembangan research \& development (R\&D) dari Borg and Gall (1983:775) yang tersiri dari sepuluh langkah yaitu :

(1) Melakukan penelitian dan pengumpulan informasi (kajian pustaka, pengamatan subyek, persiapan laporan pokok persoalan) (2) Melakukan perencanaan (pendefenisian keterampilan, perumusan tujuan, penentuan urutan 
pengajaran, dan uji coba skala keci) (3) Mengembangkan bentuk produk awal (penyiapan materi pengajaran, penyusunan buku pegangan, dan perlengkapan evaluasi) (4) melakukan uji lapangan permulaan (menggunakan 6-12 subyek) (5) melakukan revisi terhadap produk utama (sesuai dengan saran-saran dari hasil uji lapangan permulaan) (6) Melakukan uji lapangan utama (30-100 subyek) (7) Melakukan revisi produk (berdasarkan saran-saran dan hasil uji coba lapangan utama (8) Uji lapangan dengan 40-200 subyek (9) Revisi produk akhir (10) Membuat laporan mengenai produk pada jurnal, bekerja dengan penerbit yang dapat melakukan distribusi secara komersial.

\section{Hasil Dan Pembahasan}

\section{Hasil Analisis Kebutuhan}

Secara keseluruhan dari studi pendahuluan dan analisis kebutuhan terdapat dua tujuan umum yang hendak diungkap, yaitu : (1) Seberapa pentingkah pengembangan model pembelajaran lompat tinggi gaya flop diterapkan, (2) keefektivan pembelajaran model lompat tinggi gaya flop.

Berdasarkan tujuan umum tersebut maka peneliti melakukan studi pendahuluan dengan menggunakan instrument wawancara yang mendalam (in depth interview) kepada guru penjas serta melakukan survei karena tujuan utamanya adalah melakukan persiapan teknis dengan menjajaki lebih dahulu karakteristik subyek penelitian dan tempat yang akan dilakukan penelitian dan pengembangan. Hal tersebut untuk mengetahui seberapa dibutuhkan pengembangan model pembelajaran lompat tinggi gaya flop yang akan dikembangkan oleh peneliti.

Hasil studi pendahuluan atau temuan lapangan selanjutnya dideskripsikan dan dianalisis sehingga dapat diperolehsuatu rumusan hasil data yang telah dikumpulkan. Rumusan hasil ini bersifat deskriptif dan analitis, dengan mengacu kepada tujuan studi pendahuluan. Berikut ini akan dijabarkan mengenai hasil analisis kebutuhan dan temuan lapangan yang diperoleh peneliti.

Tabel 1. Hasil Analisis Kebutuhan dan Temuan Lapangan

\begin{tabular}{|c|l|l|}
\hline No & \multicolumn{1}{|c|}{ Butir Pertanyaan } & \multicolumn{2}{c|}{ Temuan lapangan } \\
\hline 1. & $\begin{array}{l}\text { Apa sajakah yang diajarkan dalam } \\
\text { dalam pembelajaran lompat tinggi } \\
\text { gaya flop bagi siswa SMP ? }\end{array}$ & $\begin{array}{l}\text { Guru mengajarkan lompat tinggi } \\
\text { langsung tanpa pengenalan gerakan } \\
\text { dasar lompat tinggi }\end{array}$ \\
\hline 2. & $\begin{array}{l}\text { Apakah materi lompat tinggi selalu } \\
\text { diberikan setiap minggu? }\end{array}$ & $\begin{array}{l}\text { Proses pembelajaran penjas tiap minggu } \\
\text { diberikan, namun lompat tinggi hanya } 2 \\
\text { kali pertemuan dalam satu semester }\end{array}$ \\
\hline 3. & $\begin{array}{l}\text { Sarana yang tersedia untuk } \\
\text { penyampaian pembelajaran lompat } \\
\text { tinggi siswa SMP? }\end{array}$ & $\begin{array}{l}\text { Terdapat beberapa alat yang menunjang } \\
\text { kegiatan proses belajar mengajar untuk } \\
\text { siswa SMP namun tidak digunakan } \\
\text { sesuai fungsinya. }\end{array}$ \\
\hline 4. & $\begin{array}{l}\text { Model pembelajaran lompat tinggi } \\
\text { yang telah digunakan selama ini? }\end{array}$ & $\begin{array}{l}\text { Tidak ada model pembelajaran khusus } \\
\text { yang digunakan. }\end{array}$ \\
\hline 5. & $\begin{array}{l}\text { Antusiasme siswa dalam mengikuti } \\
\text { pembelajaran lompat tinggi? }\end{array}$ & $\begin{array}{l}\text { Sangat bersemangat dalam mengikuti } \\
\text { pembelajaran. }\end{array}$ \\
\hline 6. & $\begin{array}{l}\text { Upaya yang sudah dilakukan agar } \\
\text { siswa tertarik dalam mengikuti } \\
\text { proses pembelajaran lompat tinggi? }\end{array}$ & $\begin{array}{l}\text { Tidak ada peningkatan proses } \\
\text { pembelajaran yang spesifik karena } \\
\text { siswa hanya bebas bermain tanpa } \\
\text { instruksi khusus dari guru. }\end{array}$ \\
\hline
\end{tabular}




\begin{tabular}{|l|l|l|}
\hline 7. & $\begin{array}{l}\text { Apakah dibutuhkan model } \\
\text { pembelajaran lompat tinggi gaya } \\
\text { flop bagi siswa SMP? }\end{array}$ & $\begin{array}{l}\text { Sangat dibutuhkan,karena dilihat dari } \\
\text { antusiasme siswa dalam mengikuti } \\
\text { pembelajaran ini diharapkan adanya } \\
\text { perubahan yang lebih baik. }\end{array}$ \\
\hline
\end{tabular}

Dari hasil pengamatan langsung di lapangan juga ditemukan: 1) Peneliti juga menemukan beberapa siswa dalam melakukan lompat tinggi masih takut dan asal-asalan. 2) Siswa masih mengalami kesulitan dalam mengatur langkah sesaat sebelum melakukan lompatan. 3) Peneliti menemukan siswa dalam melakukan lompat tinggi masih mengalami kesulitan dalam koordinasi gerak.

Uji Evektivitas Model

Setelah melalui uji coba kelompok kecil dan revisi tahap kedua komponen produk pengembangan model pembelajaran lompat tinggi gaya flop, dilanjutkan dengan uji coba lapangan dan revisi tahap ketiga komponen produk pengembangan model pembelajaran lompat tinggi gaya flop, maka untuk mengetahui rata-rata efektifitas produk, dilakukan proses implementasi dengan pengumpuln data uji efektifitas menggunakan uji $\mathrm{T}$ dengan software SPSS. Uji coba produk dilaksanakan oleh 40 siswa.

Tabel 2, Hasil Rata-rata Pretest dan Postest Uji Efektivitas Model Pembelajaran Lompat Tinggi Gaya Flop

\begin{tabular}{|c|l|c|c|}
\hline \multirow{2}{*}{ No } & \multirow{2}{*}{ Nama } & \multicolumn{2}{c|}{ Tendangan Pencak Silat } \\
\cline { 3 - 4 } & & Pre Test & Post Test \\
\hline 1 & Aris Munandar & 44 & 84 \\
\hline 2 & Agung Wijaya & 44 & 84 \\
\hline 3 & Ahmad & 48 & 86 \\
\hline 4 & Sihab & 53 & 84 \\
\hline 5 & Andi Anas & 43 & 88 \\
\hline 6 & Hendri & 47 & 85 \\
\hline 7 & Roqib & 44 & 83 \\
\hline 8 & Irfan & 49 & 84 \\
\hline 9 & M.Yunus & 47 & 85 \\
\hline 10 & Agustan & 47 & 83 \\
\hline 11 & Subhan & 47 & 84 \\
\hline 12 & Syahrul & 46 & 87 \\
\hline 13 & Dirhanuddin & 46 & 85 \\
\hline 14 & Hasan & 42 & 87 \\
\hline 15 & Taufiq & 36 & 83 \\
\hline 16 & Yogi & 36 & 84 \\
\hline 17 & Muhammad Aspar & 40 & 84 \\
\hline 18 & Rahmat & 42 & 87 \\
\hline 19 & Reza & 32 & 84 \\
\hline 20 & Juhasdi & 36 & 83 \\
\hline 21 & Dedy Riadi & & 84 \\
\hline & & 33 & \\
\hline
\end{tabular}




\begin{tabular}{|c|l|c|c|}
\hline \multirow{2}{*}{ No } & \multirow{2}{*}{ Nama } & \multicolumn{2}{c|}{ Tendangan Pencak Silat } \\
\cline { 3 - 4 } & & Pre Test & Post Test \\
\hline 22 & Arifuddin & 35 & 84 \\
\hline 23 & Hamka & 36 & 83 \\
\hline 24 & Aswandi & 35 & 85 \\
\hline 25 & Agus Salim & 34 & 84 \\
\hline 26 & Ridwan Bae & 35 & 86 \\
\hline 27 & Suhardi & 33 & 81 \\
\hline 28 & Baso Askar & 45 & 84 \\
\hline 29 & Andi Gusti & 38 & 82 \\
\hline 30 & Rudi Widodo & 49 & 82 \\
\hline 31 & Adrian & 44 & 82 \\
\hline 32 & Jusriadi & 50 & 82 \\
\hline 33 & Dahlan & 48 & 82 \\
\hline 34 & Muliadi & 47 & 85 \\
\hline 35 & Asman Ala & 46 & 82 \\
\hline 36 & Baso Oddang & 47 & 82 \\
\hline 37 & Arisal & 43 & 82 \\
\hline 38 & Hasim & 46 & 79 \\
\hline 39 & Vikis & 44 & 83 \\
\hline 40 & Asnawi & 42 & 82 \\
\hline & Jumlah Rata-Rata & 42,47 & 83,75 \\
\hline
\end{tabular}

Di atas telah dipaparkan tabel hasil rata-rata uji pre test dan post test tendangan pencak silat. Uji pre test dilakukan setelah uji kelompok besar. Pre test dilakukan sebelum menerapkan 33 model pembelajaran lompat tinggi gaya flop. Hasil rata-rata pre test pembelajaran pembelajaran lompat tinggi gaya flop yaitu 42.47 setelah dilakukan perlakuan dengan 33 model pembelajaran pembelajaran lompat tinggi gaya flop selanjutnya setelah perlakuan maka dilakukan post test atau test akhir dan nilai rata-rata post testnya adalah 83.75.

Berdasarkan uraian diatas, maka nilai rata-rata hasil pembelajaran keterampilan pencak silat antara pretest dan posttest akan diuraikan dalam Uji T Paired Sample Test dengan SPSS 16 dibawah ini.

Tabel 3. Paired Samples Statistics Lompat Tinggi Gaya Flop Paired Samples Statistics

\begin{tabular}{|cl|l|l|c|c|}
\hline & & Mean & $\mathrm{N}$ & $\begin{array}{c}\text { Std. } \\
\text { Deviation }\end{array}$ & $\begin{array}{c}\text { Std. Error } \\
\text { Mean }\end{array}$ \\
\hline Pair 1 & Pretest & 42.4750 & 40 & 5.61129 & .88722 \\
& Postest & 83.7500 & 40 & 1.82223 & .28812 \\
\hline
\end{tabular}


Berdasarkan hasil output dengan menggunakan SPSS 16 bahwa nilai ratarata hasil pembelajaran lompat tinggi gaya flop sebelum diberikan model 42.47 dan setelah diberikan perlakuan dengan model 85.75 artinya bahwa nilai rata-rata pembelajaran lompat tinggi gaya flop ada peningkatan.

Tabel 4. Paired Samples Test Lompat Tinggi Gaya Flop

Paired Samples Test

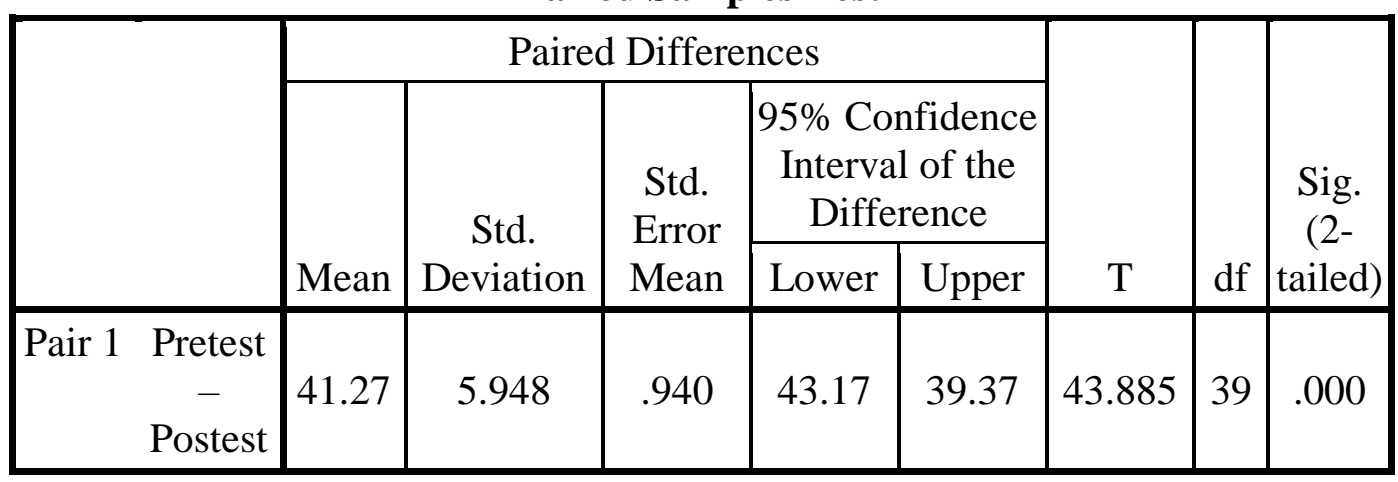

Dalam uji signifikansi perbedaan dengan SPSS 16 dapat hasil t-hitung= 43.88 , df $=39$ dan $\mathrm{p}$-value $=0.00<0.05$ yang berarti terdapat perbedaan yang signifikan pembelajaran lompat tinggi gaya flop sebelum dan sesudah adanya perlakuan model pembelajaran lompat tinggi gaya flop.

Berikut diagram perbandingan hasil rata-rata dari tingkat pembelajaran lompat tinggi gaya flop sebelum pemberian treatmen dan sesudah pemberian perlakuan dengan model-model pembelajaran lompat tinggi gaya flop dengan diagram batang pada gambar berikut ini:

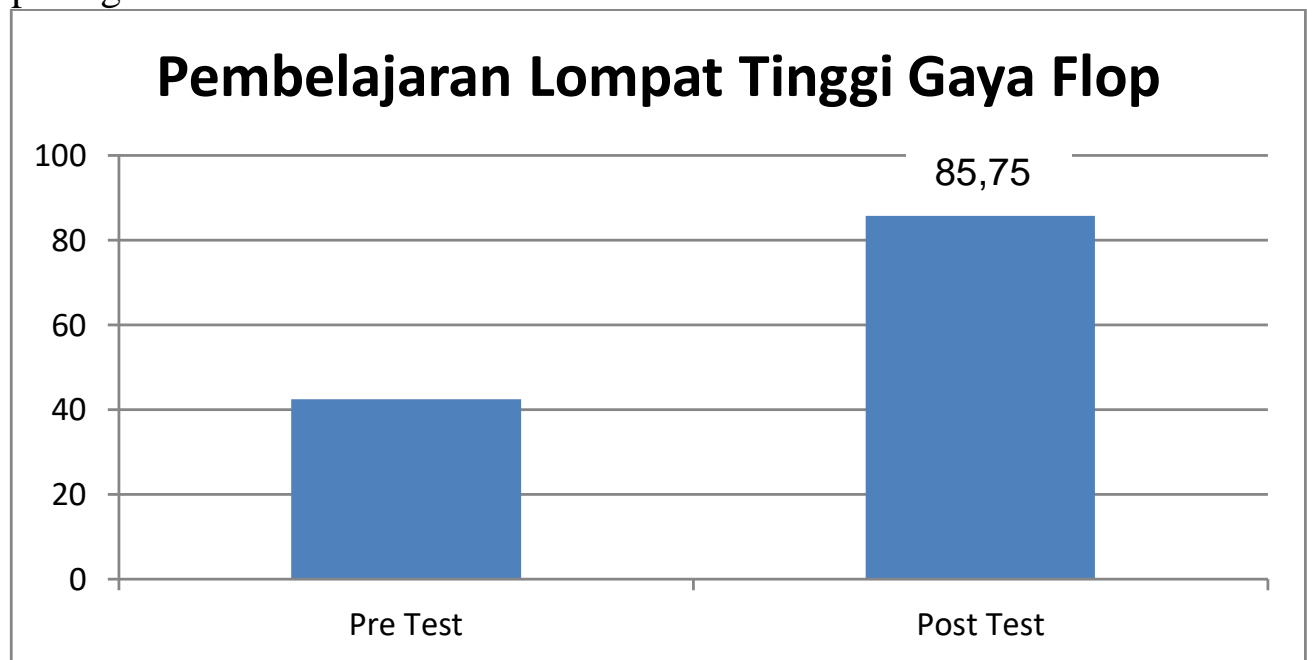

Gambar 1. Diagram Batang pembelajaran lompat tinggi gaya flop (Uji Efektivitas Model)

\section{Kesimpulan}

Berdasarkan data yang diperoleh, dari hasil uji coba lapangan dan pembahasan hasil penelitian dapat disimpulkan bahwa: 1) Dengan model pembelajaran lompat tinggi gaya flop ini, siswa dapat mempelajari dan melaksanakan pembelajaran secara efektif dan efisien. 2) Dengan materi model 
pembelajaran lompat tinggi gaya flop yang telah peneliti kembangkan, siswa dapat menguasai materi teori dan praktik lompat tinggi dengan cepat dan benar.

\section{Daftar Pustaka}

Becker, J., Kerin, D., \& Chou, L. (2012). Consequences Of Deviation From The Curve Radius In The High Jump Approach Department Of Human Physiology, University of Oregon, Eugene, OR , USA USA Track \& Field , Indianapolis , IN , USA.

Benzidane, H., Mokrani, D., Mohamed, K. S., Houcine, A., \& Sadek, Z. (2016). European Journal of Physical Education and Sport Science Effect Of Using Some Plyometric Exercises To Improve Explosive Power And Digital Achievement, 53-61.

Bradamante, F., Michelini, M., \& Stefanel, A. (2004). The Modelling in the Sport for Physics ' s Learning : Fosbury-Flop and Judo' s Cases, 206-208.

Borg. W. R \& Gall, M. D, Educational Research An Introduction, New York : Longman : 1983.

Common guideline for education research and development, USA : Institut of Education Science, 2010 .

Coaches Assosiation U.S Track \& Field, Technique For Track \& Fields ( United State : 2010, Vol. 4, Number 1, h. 16

Cheryl A. Coker,Motor Learning and Control for Practitioners, New York : McGraw-Hill, 2004.

Dapena, J. (2002). THE EVOLUTION OF HIGH JUMPING TECHNIQUE: BIOMECHANICAL ANALYSIS Jesus Dapena Indiana University, Bloomington, Indiana, USA, (Figure 3), 3-7.

David L. Gallahue, John C.Ozmun, Understanding Motor Development, Boston: MC.Graw-Hill, 2006.

Dervent, F., \& Ward, P. (2018). Transfer of Content Development Across Practica in Physical Education Teacher Education, 330-339.

Deborah A. Wuest and Charles A. Bucher, Physical Education, Exercise Science, and Sport. 16 ${ }^{\text {th }}$ Edition, New York: McGraw-Hill Co. Inc, 2009.

Hyndman, B. (2018). Note . This article will be published in a forthcoming issue of the Journal of Teaching in Physical Education. The article appears here in its accepted, peer-reviewed form, as it was provided by the submitting author . It has not been copyedited, proofread, or formatted by the.

Itamar, Gati \& Itay Asher The PIC Model for Career Decision Making, New Jersey, 2001.

Khan, A., Hussain, I., \& Mohammad, A. (2013). Effect of Different joints Velocity during Approach Run on High Jumping Performance : A Kinematic Study Department of Physical Health and Sports Education , 18(1), 22-25. https://doi.org/10.5829/idosi.mejsr.2013.18.1.11197

Leite, W. (2013). Biomechanical Analysis of Running in the High Jump, 99-105. https://doi.org/10.6084/m9.figshare.639261

Li, W., Li, H., \& Michigan, W. (2018). Note . This article will be published in a forthcoming issue of the Journal of Teaching in Physical Education . The article appears here in its accepted, peer-reviewed form, as it was provided by the submitting author. It has not been copyedited, proofread, or formatted by the. 
Meredith D. Gall \& Joyce P. Gall W. R. Borg, Eight Edition Educational Research, USA : 2007.

Punaji Setyosari, Metode Penelitian Pendidikan dan Pengembangan, Jakarta: Pranada Media Group, 2013.

Rade Stefanofic, 2015Annex To The Training Technique High Jump ( Serbia : Faculty of Sport and Pyhsical Education,) Vol. 5, No. 2, pp 227-230, h. 227

Rao, D. C. V., \& rao, D. C. R. (2016). Kinematic Analysis of Take off Technique on the Performance of the Fosbury Flop. IOSR Journal of Sports and Physical Education, 03(03), 17-20. https://doi.org/10.9790/6737-03031720

Rao, C. R., Kishore, P. Y., \& Rao, J. R. (2014). Biomechanical Analysis of Centre of Mass Height during the Takeoff Phase In Fosbury Flop High Jump of National Level Participants, (10), 8-10.

Robert Maribe Branch, Instructional Design: The ADDIE Approach, New York: Springer, 2009.

Science, S., Science, N., \& Education, P. (2014). Role of different joints velocity during approach run on high jump performance: a biomechanical study asim khan 1 , ikram hussain $21,1,57-62$.

Song, W. Z. (2013). Study on the analysis and simulation of fosbury flop technique based on the sports biomechanics. BioTechnology: An Indian Journal, $8(10), 1331-1336$.

Sugiyono, Metode Penelitian Kuantitatif, Bandung : Alfabeta, 2009.

Sami Kalaja, A Fundamental Movement Skill Interventions, Jyvaskyla: University Jyvaskyla, 2012.

Tan, J. C. C., \& Yeadon, M. R. (2005). Why do high jumpers use a curved approach? Journal of Sports Sciences, 23(8), 775-780. https://doi.org/10.1080/02640410400021534

Trianto, Model Pembelajaran Terpadu dalam Teori dan Praktek, Surabaya : Pustaka Ilmu, 2007.

Vladimir B. Issurin, New Horizons for the Methodology and Physiology of Training Periodization, Israel : SportMed, 2010.

Wilson, C., King, M. A., \& Yeadon, M. R. (2011). The effects of initial conditions and takeoff technique on running jumps for height and distance. Journal of Biomechanics, 44 (12), 2207-2212. https://doi.org/10.1016/j.jbiomech.2011.06.01 